\title{
DOI: 10.7596/taksad.v9i3.2656
}

Citation: Verkina, T., Bondarenko, M., Sagalova, A., \& Timofeyeva, K. (2020). The Performing Art as a Practice of Actual Intoning. Journal of History Culture and Art Research, 9(3), 17-28. doi:http://dx.doi.org/10.7596/taksad.v9i3.2656

\section{The Performing Art as a Practice of Actual Intoning}

\author{
Tatyana Verkina ${ }^{1}$, Maria Bondarenko ${ }^{2}$, Anna Sagalova ${ }^{3}$, Kira Timofeyeva ${ }^{4}$
}

\section{Abstract}

The article considers the musical and performing arts as a special creative practice, i.e. as a special way of anchoring, recreating, and developing a person's musical experience through musical intoning. Musical performing practice functions as an oral discourse and includes, in addition to the text itself (the original one - the note text, and the resulting one - the acoustic text), the processes of its creation and understanding that are unfolding themselves in time. Musical and performing art accumulates its experience of intoning, first of all, in the real sound practice. It is in the process of performance that music is actualized, gaining an existence in time in the living intoning. Intoning is presented as a process of a special kind of communicative relations and is generalized through several concepts and categories of the style level which are associated with performance (the performing practice, performing dramaturgy, and performing style). One of the specific styles that are most illustrative in terms of solving the artistic and technical problems of a complex order is the piano performance (wider - the pianism). The development and enrichment of the existing music experience is only possible in its actualization. Musical art is revealed as the "actual being of a composition" in the process of performing it for listeners, on a specific instrument, in a particular hall.

Keywords: Piano performance, auditory presentation, performing practice, actual intoning, performing dramaturgy, performing style.

\footnotetext{
${ }^{1}$ Kharkiv National University of Arts named after I. P. Kotlyarevsky, Ukraine. http://orcid.org/0000-0002-15411959 E-mail: tverkina@gmail.com

${ }^{2}$ Kharkiv National University of Arts named after I. P. Kotlyarevsky, Ukraine. http://orcid.org/0000-0001-5193$\underline{2535}$ E-mail: mariia_bondarenko@ukr.net

${ }^{3}$ Kharkiv National University of Arts named after I. P. Kotlyarevsky, Ukraine. http://orcid.org/0000-0002-70370555 E-mail: anna.sagalova@gmail.com

${ }^{4}$ Kharkiv National University of Arts named after I. P. Kotlyarevsky, Ukraine. http://orcid.org/0000-0001-5411$\underline{7253}$ E-mail: k.timofeieva@gmail.com
} 


\section{Introduction}

In the contemporary musicology, one of the central issues is the performing phenomenon, which is directly related to the performing practice, the interpretative nature of music as the art of sounds in time. Performance in the system of the morphology of arts is classified in two ways: on the one hand, it is thought of as "secondary", subordinate, dependent on the design of the author of the composition; on the other hand, performance is included into the system of kinds of art itself. The philosophical and aesthetic understanding of the phenomenon of performance in music is presented in the monograph by M. Kagan (1972), where the performing arts (music, theatre) are distinguished as independent, in one line with other kinds - both spatial and temporal. While discussing the place of the performer in musical culture, G. Ordzhonikidze considers the two terms related to that "performance" and "interpretation". The author notes, in particular, that "...there is no poorer term than "the performer" (Ordzhonikidze, 1971, p.64), since this is a question of the fulfilment of the other's will, in this case, of the composer's as the author of the musical text. More successful, according to the musicologist, is the term "interpretation".

Practice in the broad sense means "different ways of realizing human existence in different forms of anchoring, recreation and development of human experience, the process of transition of the experience, which was accumulated and is being accumulated, in the conditions of their existence, into the means of their activity, in the schemes of their self-assertion" (Modern Philosophical Dictionary, 2004, p.544). Based on this definition, one can assume that musical performance is a special kind of creative practice. It is a "way of anchoring, recreating and developing" a person's musical experience, a "process of transition" of the experience recorded in the corpus of musical note texts and in the traditions of their reading and accumulated by musical art into the conditions of its existence, into the means of activity of musicians, into the schemes of their self-assertion.

The practical activity of the performer is a kind of a "reconstruction" of the artistic whole by its individual, more or less described details. Performance also implements the idea of translating - "to learn a musical note text - means to translate it into the finger movements on the keys" (Hesse, 1992). Of course, this is not just an attempt to play as it will turn out. It is a great job to achieve the desired result. The performer makes a conscious choice in the given conditions. This makes it possible to find one's way, one's solution.

In his article "On translation" (1966), R. Jacobson sees the main problem with translation not in expressing the meaning unambiguously, but in preserving the ambiguity of the source language (Jacobson, 1966, p. 12). The sound realization of the musical text also gives the listener sufficient freedom to interpret the artistic image, which is as meaningful as its graphic prototype.

In the most general terms, performing practice implements the idea of "playing". There is a profound pattern in the fact that G. G. Neuhaus called his work on piano performance "The Art of Piano Playing" (1958).

The famous linguist A. Vezhbitskaya, when speaking of semantic primitives, suggested the following interpretation of the playing:

“(a) much of what is done by people;

(b) people have been doing this for a long time;

(c) people do it for pleasure (i.e., they want to experience some good feelings);

(d) when they do this, they want something to happen;

(e) if they did not do this, they would not want something to happen; 
(f) when they do this, they must know what they can do;

(g) when they do this, they must know what they cannot do;

(h) before people do this, someone must tell them this" (1996, p. 213).

Of course, as the playing, musical performance refers only to human activities, the product of these activities has its duration and "cannot be instantaneous." Its purpose, in the final sense, is the pleasure of both the performer himself/herself and the listener, "involved" in the playing as the subject of communication. It would be desirable, following V. Savchuk, to warn against the advertising understanding of pleasure: "Pleasure requires effort, effort requires sympathy and suffering, sympathy and suffering require pain and joy and, finally, admiration" (2004, p. 96). Like the playing, the process of performance is "excluded" from ordinary reality, one of its goals is to recreate a different, artistic, world and invite the audience there. Limited by the musical text, the artistic tradition, the performermusician acts within the strictly defined "written" and "unwritten" rules that form a certain musicallinguistic canon. However, this does not preclude freedom of choice. In every historical era, the sector of the performer's freedom changes. But under the most severe conditionality, every performance act is virtually unpredictable; no one - either the listener or the performer - knows exactly what will happen at the moment of performance and what will be its result - the reaction of the public. Finally, in order to perform music, it is necessary (at least at the initial stage of studying) to receive the instruction from a competent person (and more than during one year) for this purpose.

\section{Methods}

The methodological basis of the article is the interaction of several scientific approaches of the modern musicology, among which there is:

- a systemic one, studying phenomena and processes in the unity of subject, functional and historical planes;

- a semiotic one, acting through the deciphering of senses and meanings in music (through the system of musical signs and symbols) in a particular historical context;

- an interpretative one, allowing to reveal the specificity of phenomena and artefacts of the performing art and focusing the peculiarity of the principles of the performing thinking (in particular, the performing text, intoning, dramaturgy, and style);

- a style one, differentiating the creative activity of the composer and musician-performer in the aspect of personality, located around their artistic awareness and the system of principles of musical thinking.

\section{Results and discussion}

In the context of the performing art, the Russian word "playing" is more closely related to the German word "Spiel", which has a wider range of use corresponding to the English "playing" (though inaccurate). At the same time, the German word "Spiel" also expresses the idea of rules (the prior knowledge of what can be done and what cannot be done) and the idea of a well-defined goal that may or may not be achieved (Vezhbitskaya, 1996).

A wonderful metaphor for musical performance can be the "glass bead game" by $\mathrm{H}$. Hesse, which is understood "as a way from becoming to being, from the possible to the real" (1992). "The rules of this game cannot be learned in any other way than the usual, prescribed way, which takes years" (Hesse, 1992, p. 24). "Within this firmly established system, a whole world of possibilities and combinations is open to the individual master of the Game" (Hesse, 1992, p. 25). 
Playing the instrument, like "the glass beads game" is "not just an exercise, not just a rest," but it, in Hesse's opinion, - "embodied the proud discipline of the mind... They played it with ascetic and at the same time sporting virtuosity and meticulous rigor, finding pleasure in it" (Hesse, 1992, p. 40).

In order to prevent the game "signs" from turning into plain letters, the professional glass beads players - the citizens of Castalia introduced the obligatory inclusion of "contemplation experience" into the gaming activity - "a requirement of a deeper and more spiritual dedication, a quiet, rigorous reflection on this sign, its content, origin, meaning..." (Hesse, 1992, p. 44). This made it possible to perceive the "game signs" as peculiar hieroglyphs.

In musical performance such "hieroglyph of the game" is intonation. "Intonation in music science and practical musicianship means something understandable and difficult to perceive. In essence, this is the quality of meaningfulness - the understanding of music, of its performance" (Tarayeva, 2000, p. 7).

The researchers refer the origin of this musical term to the time of the codification of the church choral by Pope Gregory the Great in the 6th century and the creation of "Antiphonarium" for the choir and "Cantatorium" for the solo performance of psalms by the deacon. Within the framework of "Cantatorium" certain recitative forms, chants, recited "in one tone "recto tono", were formed. This single note, on which all the syllables of the text sound, is framed by very short melodic episodes, the introductory intonation, the interrupting mediatio, the final punctum (Oder, 2004, p. 133).

B.V. Asafyev rightly stated that "the quality of the introductory tone is one of the most important stimuli for the growth of European music and the "first engine" of the European synthesized fret: it is the stimulus of the fret, its "verb"'" (1971, p. 229). Long before B.V. Asafyev, the French philosopher D. Diderot called intonation a "nursery of melody" (Materials and Documents on the History of Music, 1934, p. 478).

Why is the introductory tone playing such a role in music? V.M. Rozin suggests that "the musical reality during its formation relied on a quite definite experience of human feelings. One of the peculiarities of this experience is the connection with ...the reality of "I", the other is the conditionality of the subsequent events by the previous ones or the close relationship of them... Probably, therefore, the introductory elements of music <...> that immerse a person into the experiences of his/her "I" serve as guides in this reality, and act as its origin and focus" $(1988$, p. 25).

According to B. Asafyev, intoning is a "manifestation of thought." "The thought, in order to become acoustically expressed, becomes intonation and transforms into a unity, a rhythm-intonation of the word-tone, into a new quality, rich in expressive possibilities" (1971, p. 211). The idea of a musical language in a metaphorical sense has existed since the times of I. Kant, who called music "the language of affects". In the second half of the 19th century, two different directions in the study of music were identified. One of them is related to the name of G. Riemann (1849-1919) and promotes the formal and technical analysis of linguistic means of a musical composition. Another direction was initiated by the Swiss musicologist E. Kurt (1886-1946), who offered a procedural-dynamic interpretation of harmony, an in-depth analysis of its emotional and psychic peculiarities.

The views of B. Asafyev are close to the views of E. Kurt. The intonation theory by B.V. Asafyev became the basis for Russian and Ukrainian musicology. As it is known, he also defined music as "the art of intoned meaning" and gave definitions to musical intonation, "an intonation dictionary of the era", "an intonation crisis". B.V. Asafyev considered the origin and development of musical intonation, its connection with the speech one.

The comparison of speech intonation and musical intonation is sufficiently deeply developed in music studies. For the first time the idea of music as a specific language, which historically and at the 
level of the world view provides the connection between the composer and the listener, was expressed by $\mathrm{B}$. Yavorsky. In his understanding, the musical language is no longer a metaphor, but a strict concept.

The theory of intonation has been widely developed. In line with the tradition of B. Asafyev and B. Yavorsky there goes, for example, the etymological method of research by I. Barsova, who connects the importance of musical intonation to the lexeme. In the musical intoneme, as in the lexeme, one can discover its forgotten lost meaning by tracing the fate of the long-established musical turns rhetorical figures, the meaning of which is transformed in the context one moment, and the other moment it remains unchanged (Tarayeva, 2000).

A. Sokolov considers the distinction between speech intonation and musical intonation, the concomitant nature of the verbal intoneme and the independent character of the musical one, which is close to the lexeme, but without the strict limitation of its meaning. He also distinguishes between different ways of the pitch organization of musical and speech intonation.

Characterizing a wide range of semantic content of intonations, V. Medushevsky subdivides them into the emotional-expressive, object-representational, musical-genre, and musical-style ones; from a scale-time point of view intonations are subdivided into "the detailing intonations of certain moments, the intonations of individual constructions and themes, and the generalizing intonation of the whole composition" (1991).

V. Kholopova adds here the intonations of the individual means typified in music (fret-harmonic, rhythmic, timbre, etc.).

Intonation is a part of the system of the sound means of the verbal language along with phonemes (in all the variety of their sound realizations) and verbal emphasis. Each of these means is differently involved in expressing the semantic and emotional content of speech. As in music, intonation is an integral part of the oral speech practice, and becoming an object of study in linguistics. Speech intonation, like the musical one, conveys information about what is being said, who, how (in what condition) is speaking, where (in what situation), to whom (to which interlocutor). If the question "what is being said?" is certainly responded by linguistics, while revealing the semantics of intonation, the totality of its transmitted values, the questions "how?", and especially "who?" is speaking and "where?" have always been on the verge of proper linguistic interests (Svetozarova, 1982, p. 9). The search for the answer to the question "who is speaking?" is related to the recognition of the personality or the identification of the speaker's voice. The question "how is he/she speaking?" opens the prospect of studying the interaction of "speech" and "emotions". This scientific direction is internally heterogeneous. Linguistics studies the linguistic means of expressing specific emotions and their perception, and the field of diagnostics of mental illnesses associated with the study of speech pathologies is singled out. The connection between intonation and the emotional sphere of the right hemisphere of the brain, specific-figurative thinking of a person has long been known (Svetozarova, 1982).

There are a great number of definitions of intonation, different from each other both in form and in substance. In the work called "The Intonation System of the Russian Language" (1982), N.D. Svetozarova defines intonation as "the totality of prosodic means involved in the division and organization of the speech flow in accordance with the meaning of the transmitted message" (Svetozarova, 1982, p. 15).

The founder of the functional approach to intonation, the Czech linguist F. Danes called the following primary functions of intonation:

1) turning words (called units) into a statement (communicative units). Intonation is the means of creating a statement. In an isolated statement, intonation unites its elements. In a coherent section of speech, it also separates the statements from each other; 
2) signalling about the ratio of theme and rheme, as well as to characterize the purpose of the statement, its emotional fullness.

In the collective monograph "Intonation", the emotional or expressive function of intonation is excluded from the linguistic description, while the attention is concentrated on the function of articulation, the function of connection, the function of the transfer of semantic relations. Intonation provides organization and articulation of the speech flow (Svetozarova, 1982). To do this, punctuation signs, pauses between words, combining words related in meaning are used. The word groups, divided by pauses, are different in size, structure, and degree of independence from the neighbouring groups. Within the statement, syntagmas and rhythmic groups are formed, and among them certain semantic connections occur. A pause is an articulation signal. Scientists note the difference in the nature of pauses.

The intonation means of speech include differences in its pace, intensity, and melodic design. This includes the notion of logical emphasis - the "intonation semantic centre".

Within the emotional function of intonation, N.D. Svetozarova identifies two different spheres:

1) emotional significance (doubt, categoricity, regret, challenge, reproach);

2 ) the sphere of general emotional colouring, emotional states, and moods.

In the first case, the language specificity that is deliberately modelled is revealed. In the second case, the involuntarily expressed universal values, directly stipulated physiologically, are revealed. Specific intonation units are formed only in the sphere of emotional values (special emotional contours, emotional variants of intonation constructions with the use of timbre, duration and melodic configuration), and the overall emotional colouring is achieved by the modification of the entire intonation pattern (using differences in tempo and the general level of intensity and pitch).

In semiotic terms, J. Austin and J. Searle distinguish four levels of a speech act: locution, proposition, illocution, and perlocution. A speech act as an activity involves formal and substantive parts. The formal one includes linguistic units, and the substantive one includes propositional values and programmatic components in the form of an illocutionary function of a speech act. Intonation provides illocutionary functions of a statement that reveal the communicative intent of the speaker, allowing to influence the addressee and to cause changes in the addressee's world which correspond the intention" (Searle J., 2002, p. 52).

The real language practice in modern linguistics is commonly referred to as a discourse. The discourse emerges as the unity of the process of linguistic activity and its result, that is, a text. "A text is a static object that arises in the course of the language activity. It can be a written text, i.e. a sequence of graphic symbols, and it can be an oral one - an acoustic signal that can be fixed, for example, on a tape recorder" (Kibrik, 2003, p. 4). The discourse is related to the presence of "a sender" and "a recipient" of information. The contraposition of the role of the speaker and the listener determines two directions of research in linguistics. The authors of one of them are engaged in the study of the processes of generation, "the synthesis of the discourse", the authors of the other are engaged in modelling the processes of understanding, "the analysis of the discourse"). Musical performance in the aspect of artistic interpretation appears as the modelling of the processes of understanding (analysis) of the discourse. But musical performance can and should be studied as a practice of the construction (synthesis) of the discourse. In the present article, the perspective of the "speaker" is taken as the basis, therefore, the process of the creation (i.e., genesis) of a discursive form, which is a sounding musical text, is considered.

As a sound phenomenon, music forms a complex multidimensional structure. "In a musical notation, the number of measurements is usually equal to two - high-pitch and rhythmic... Only rarely the third dimension, expressed in dynamic nuances, is added - depth. This coordinate is very important 
for an expressive performance, for separating the relief from the background" (Rugs, 1999, p. 185). The music recorded in the note text exists as if it were "in the archive" on the plane of a sheet, devoid of being in the real time. In fact, the musical notation contains only "business information", the performer makes it artistic.

In other words, the musical experience accumulated in the written media is transmitted by the performer in an "actuality" mode. In the context of music-performing practice, "actuality" is understood, first, literally, as the sound form of the being of a musical composition, and secondly, as a specific quality of a performance text, which represents its present, momentary status, provokes questions about today and is a symptom of a specific place and time. Musical performance deals with the "unstable and flowing now", which "possesses the power only when it is able to answer the challenge of accelerating time, which means that it is necessary to abandon the usual course of things, to change symbolic and ideological baggage and, finally, to enrol oneself into the horizon of the present" (Savchuk, 2004, p. 4). The musician-performer is constantly in search of the "present", which is lost by the note text, and which becomes meaningful only after passing the stage of collective attention - the same relevance.

The main performance problem is an "actual intoning", which allows not only to record sound to the musical text as "spoken" by a particular person here and now, but also to present to a specific audience the sounding as filled with the actual meaning, significant for the present, and therefore worthy of being in the future (Verkina, 2008).

The composer's note text must be recreated as if from the first person. "It is necessary to get involved in the material, to make it your own experience, your own spiritual experience" (Zhukov, 2007 , p. 9). However, this is not the practice of the appropriation of a "stranger's" text, which is fraught with banality. One can even fall into banality actively not wanting it to happen. It is necessary to "be careful - to be on the guard of beauty. Not prettiness. Prettiness is stereotyped in its essence. Beauty is unique and makes an impression when it is, as they say, in place. There is no beauty at all, the banality is a "good piano sound", an "artistic performance" (Zhukov, 2007, p. 10).

The performance that turns everything into banality renders a verdict on works of art. It "casts the cover of common places on the present moment to make the face of reality disappear" (Kundera, 2004, pp. 147-148). Therefore, the musician-performer must always be thirsty for concreteness. "The search for the lost present, the search for the melodic truth of the moment; the desire to take by surprise and catch this slipping truth; the desire to penetrate, thus, into the mystery of immediate life, which therefore becomes one of the most unknown things in the world" (Kundera, 2004, p. 140) - this is the ontological meaning of the musical and performing art.

The ability to intone is a quality that is least amenable to an analytical approach, but ultimately determines the level of artistic performance of a composition; the means of expression that does not imply fixation in the musical notation, which depends solely on the degree of the musician's talent. With the utmost importance of the whole complex of expressive means in any musical composition, in the creativity of each composer, one or several qualities, which allow defining his/her style, undoubtedly stand out.

The creative practice of the musician-performer, on the one hand, is focused on communicating with the composer's personality, understanding the musical text and finding ways to present it in real sound. On the other hand, the performer not only recreates the composer's product, but creates its sound equivalent, playing with the signs and meanings of culture, addressing the contemporaries, talking about him/her. It is a kind of work in the given conditions, which requires the search for one's solution, one's way. 
One of the key concepts of musical performance is the "text" considered in the aspect of musical communication: a composer's text representing the intonation-dramaturgical structure of a musical composition, and a performer's text viewed from the standpoint of performing thinking through the dichotomy of "dramaturgy-concept". If a musicologist views a musical composition as a semiotic object, then for the performer, a musical composition is a performing process: an intonationdramaturgical form, which is fixed in the author's text, becoming in time. Studying a musical composition, the performer as the co-creator recreates (each time anew) the author's text, in which case the end result of this creative process reflects the performer's plan of expression of the author's concept. In this case, the composition acquires a new dimension of the artistic meaning of music - the performer's interpretation.

The notion of interpretation covers, as it is known, a wide range of phenomena and is connected with almost any way of reading any artistic text. At the same time, the main tendency of the professional performing art was and is the special attention, the thoroughness of the composer's instructions concerning all the parameters of the musical notation (dynamics, articulation, phrasing, agogic, and figurative content). Thus, the will of the performer as an interpreter is usually manifested in the expressiveness of the pronunciation of the intonation structure of the text, in his/her personal reaction to harmonic tendencies, in the construction of a convincing form and dramaturgy of the composition, which, of course, already depends on the level of the musician's culture (Bondarenko, 2007).

In the process of working on a composition, one of the most important tasks becomes the intonation filling of music - the increased attention to the interval as the most important structural cell of all musical fabric, and, consequently, the careful intonation work. The precise execution of the author's instructions, as well as the understanding of the specifics of the musical language leads to an intonationally rich and expressive performance.

The concept of a "musical text" is multifunctional and contains various approaches to its definition. In the musicological environment, the text is studied as a source of information, its structural side is analysed, and the performer as an intermediary between the composer and the listener seeks to identify the semantic side of the musical text.

Let us construct the definitions of "musical dramaturgy", proposed by the theoretical musicology, in terms of their practical orientation to solving performing tasks. According to $\mathrm{V}$. Bobrovsky's definition, focused on a musical composition, "musical dramaturgy is a plan and a line of development of the moments of musical time which are essential for the realization of an artistic idea" $(1978$, p. 77$)$. If the compositional basis of a musical composition conveys its structure, then the dramaturgy reflects the inner content. However, if the author considers the compositional and dramaturgical functions of a musical composition in dialectical unity, then for the performer the dramaturgic functions dominate the compositional ones.

In continuation of the functional approach to the musical form set out in the works by $\mathrm{V}$. Bobrovsky, V. Medushevsky puts forward the idea of the duality of the musical form. In particular, the researcher presents the semantic opposition "composition - dramaturgy" as musical universals, whose action is found at the deepest level as the reduced form and the expanded form.

The comparison of the substantive, functional and structural characteristics of the reduced and expanded form shows that the essence and completeness of the artistic image in music is revealed by the expanded form, the creator of which is the actual performer-interpreter. Therefore, all of the above stated by $\mathrm{V}$. Medushevsky about the expanded form coincides with the semantics of the performance process, with what constitutes the content of the concept of "the performance dramaturgy". In other words, the depth and content of the performer's interpretation of the 
composer's concept are fundamental differences in the personal reading of one musician or another, which are a certain complex - performance dramaturgy.

The performing recreation of the expanded form creates performance dramaturgy, which includes a certain system of semantic interrelations:

- the composer's concept of the composition (it is expressed in the musical notation);

- the performer's concept or the performer's idea (the embodiment of the composer's idea through the intonation filling of the musical composition by the performer);

- the ratio of time and space in the performance process (the individual feeling of the moving form by a particular performer, depending on psychophysiological peculiarities, intelligence, musical talent, and the ability to intone).

The intonation richness of the musical fabric is so great that it is possible to change in a virtually unrecognizable way the same construction while repeating only at the expense of the redistribution of the significance of the intervals, and, consequently, the time of their utterance. Moreover, depending on the location of the "main" interval, the temporal structure of the whole construction, be it a melodic line or a passage ${ }^{5}$, is transformed. Of course, such intonation work cannot be performed exclusively at the moment of a concert performance, that is, it is not a pure improvisation, but as a result, every performance decision may be somewhat unexpected for the listener. As we can see, with this approach, the agogic changes at the level of short motive constructions, very often - even of the separate intervals, take on a tremendous importance in music.

The dramaturgical processes contained in a musical composition (in genre, style) are revealed in the performance activity through the creative personality of the interpreter. While analysing the author's text of a well-known classical composition, or getting acquainted with a new composition from the author's manuscript, the performer acts here as an interpreter-analyst (the reduced form level). When the composition under study becomes a real artefact (in concert conditions or in a studio recording), in this case its perception and analysis are the content of the expanded form. The criterion for the differences between these two sides of the performing reading of the musical form as an aesthetic value is the completeness of artistic embodiment. According to V. Medushevsky, "the path from the reduced form to the expanded one lies through the image" $(1979$, p. 182). Let us add a significant correction - the performance image! Thus, the unity of the reduced and expanded form constitutes the performance concept of the composition.

Seeking to be closer to the "spirit and letter" of the author, the performer builds his/her interpretation of the composition, based on the decryption of the reduced form. The performing "modelling", that is, the actual recreation of the expanded form, gives birth to the performance dramaturgy - an individual plan of expression of the composer's concept, which constitutes a complete system of artistic images, an intonation structure on the basis of which the creative principles of the performer's interpretations are expressed (Timofeyeva, 2009).

In the creation of the performance dramaturgy, the peculiarities of the performance style become an important step. These two concepts are interconnected: on the one hand, the performance style directly influences the character of the performance dramaturgy, the construction of the performance concept, on the other hand, having revealed the features of the performance dramaturgy of a particular performer, we reach a higher level in understanding the performance style (new nuances, the features of interpretation are opened).

\footnotetext{
${ }^{5}$ This refers to the so-called "ricochet principle", when the time of pronouncing intervals within a phrase depends on the degree of stress at the culmination point: the stronger this tension, the faster the "end" is reached; the further from the beginning of the musical "word" its "stressed syllable", the more rapid the approach to it.
} 
Considering style in music as a complete artistic phenomenon, encompassing all kinds of musical creativity, they are usually guided by the famous axiom put forward by the 19th-century art historian George Duffon - "Style is a human."

The approach to performance as to an independent creative act determines the stylistic interpretation of this phenomenon. From the point of view of the theory of style in music, developed in the works of a number of musicologists, in particular, in the works by M. Mikhailov (1981), A. Sohor (1981), V. Kholopova (2000), V. Moskalenko (1994), O. Katrich (2000), the performing style refers to the category of creative personalities' styles. This means that in the hierarchical system of the style classification, the performing style, as well as the composing and the musicological ones, are located between the type style, according to V. Kholopova, "the style of any kind of music" (for example, the piano style) and the style of one, as a rule, epochal composition (2000, p.223).

The performing style as a style of a creative personality is not limited to only the individual aspect. Each level of style is embodied in the unity of individual and beyond-individual beginnings, and this allows seeing in the performing style the lines of "horizontal" and "vertical" inter-style communication (Sagalova, 2017). The first line (horizontal) characterizes the style communication of the performer with other subjects of Asafyev's communicative triad - "composer - performer listener". The second line (vertical) means the assimilation in the individual performing style of normsigns of other levels of the style hierarchy - epochal, national, "school", and "compositional". Therefore, the performing style in musical art appears as a complex, synthetic category.

Intoning thus appears as a process of a special kind of communicative relationships and is generalized through a number of concepts and categories of the style level associated with performance. According to A. Malinkovskaya, the intonation concept of musical art is a "common core, a centre"; it is a factor of "fundamentalization" and centralization of problems of music science as a whole" (2012).

The creative activity of a musician is always determined by the parameters of his/her main specialization: the performer is oriented to the theory and practice of this kind of a music profession; the composer - to the relevant principles and standards of musical writing. However, within these specializations, which are generic in the levels of generalization, there are many types of style nuances. These "images" are formed within a broader concept and phenomenon, defined as the "piano culture", which has a direct relation to the question of the nature of the performing art.

\section{Conclusions}

Musical performance as a communicative practice is the sphere of realization of the effective experience of the musician, the experience of reproduced and consolidated productive work as an application, embodiment and testing of human skills, abilities and knowledge. The activity of the musician-performer is subordinated to the idea of returning to the musical notation of the "lost present" through actual intoning. Intoning as a special kind of artistic activity actualises the musical texts recorded in the musical notation, transforming the written discourse into the oral one. The musicians-performers "resurrect" the time destroyed by the composers, find their own ways of detecting it, create "the passage of time", not only by drawing certain meaning leagues in the composition, but at the same time as though depicting its "genealogy".

Style (including the performance one) as a kind of "fixation" of something (for example, of a worldview) in some constants may be "irrelevant", intoning is always manifested through actualization.

Musical and performing creativity represents, on the one hand, a special morphological unit, in the system of kinds of art, on the other hand, is a specific activity of the secondary-reproductive order. At the basis of this relationship, there is a categorical pair of concepts of "performance" and 
"interpretation", where the first means the reproduction of the author's text of the composition, and the second means its deeper, individual-personal interpretation. Musical and performing art acts as a stylistic phenomenon, in the centre of which there is the figure of the musician-performer, as well as the "tool" of his/her activity - the instrument (or the voice) with help of which he/she expresses "himself/herself in the other".

Based on a deep study of the author's text, the performer recreates the intonation dramaturgy of the musical composition, which is the basic foundation for the search for interpretation, while the multiplicity of performing concepts grows on its objective basis. Performing dramaturgy is the foundation in relation to the performing style and creates the meaning for other, higher levels of the organization of the performing process: the performing concept, the performing style, the performing school.

Thus, one of the major and large-scale, by the effects and technical capabilities, factors of the cultural and performance process is the piano performance - the pianism, the impact of which on the general system of musical performance determines the need for its multidimensional study.

\section{References}

Asafyev, B. (1971). Musical form as a process (2nd ed.). Music, Leningrad department.

Bobrovsky, V. P. (1978). Functional basis of musical form: research. Moscow.

Bondarenko, M. V. (2007). Textural features of F. Chopin's piano concerts as a reflection of the romantic tendencies of the genre development. Problems of interaction among art, pedagogy and theory and practice of education, 20. Kharkov.

Hesse, H. (1992). Glass beads game. Moscow: Pravda.

Jacobson R. (1987). Works on poetics. Moscow: Progress.

Kagan, M. (1972). Morphology of art. Moscow: Art.

Katrich, O. T. (2000). Individual style of the musician-performer (theoretical and aesthetic aspects). The author's abstract of the dissertation on acquiring a scientific degree of the Candidate of Art Criticism. Kiev.

Kholopova, V. N. (2000). Music as an art form. Moscow: Lan'.

Kibrik, A. A. (2003). Discourse analysis in a cognitive perspective: dissertation in the form of a science report on acquiring a degree of Doctor of Philology. Specialty 10.02.19 "Theory of Language". Moscow: RAS, Institute of Linguistics.

Kundera, M. (2004). Broken testaments. St. Petersburg: Alphabet-Classics.

Malinkovskaya, A. (2012). The theory of the piano intoning has always been, still ahead. Moscow: The Gnesin Russian Academy of Music.

Medushevsky, V. V. (1979). About musical universals. Articles and memories. Moscow.

Medushevsky, V. (1991). Fantasy in culture and music. In M. L. Muginstein (ed.), Music. Culture. Man. Collection of Articles. Sverdlovsk. 
Mikhailov, M. K. (1981). Style in music. Research. Music, Leningrad.

Moskalenko, V. G. (1994). Creative aspect of musical interpretation. Research. Kiev.

Music history materials and documents. (1934). In 2 volumes Volume 2. XVIII century (Italy. France. Germany. England). Translated from Italian, French, German and English. Edited by M.V. IvanovBoretsky.

Neuhaus, G. G. (1958). About the art of piano playing.

Oder, A. (2004). Musical forms. Translated from French by V. Shabayeva. Moscow: AST Astrel.

Ordzhonikidze, G. (1971). The role of creative individuality in the formation of national style. Soviet Music, 9, 13-29.

Rozin, V. M. (1988). Exploration of musical reality and expressive means of music. Expressive means of music: inter-university collection. Krasnoyarsk. Publishing House of Krasnoyarsk University, 6-26.

Rugs, Y. N. (1999). Aesthetics below and aesthetics above - quantitative ways of convergence: a study. Moscow: Scientific world.

Sagalova, A. (2017). Performing school in piano art: the concept of leadership (on the example of creativity of T.B. Verkina). Problems of interaction among art, pedagogy and theory and practice of education, 46, 131-143.

Savchuk, V. (2004). Actuality mode. St. Petersburg.

Searle, J. (2002). Reopening consciousness again: translated from English by A. F. Gryaznov. Moscow: Idea-Press.

Sohor, A. (1981). The aesthetic nature of the genre in music. Questions of sociology and aesthetics of music. Collection of articles. Leningrad, 2, 144-158.

Svetozarova, N. D. (1982). Intonation system of the Russian language. Leningrad.

Contemporary philosophical dictionary (3rd ed.). (2004). V. E. Kemerov (ed.).

Tarayeva, G. (1967-1997). Intonation - image, style, epoch. 30 years of conservatory science. Research and Practice Conference of teachers and graduates of RSK, Rostov-N/D: Tera, 6-8.

Timofeyeva, K. V. (2009). Comparative analysis as a method of interpretation science (on the example of piano performance). The author's abstract of the dissertation on acquiring a scientific degree of the Candidate of Art Criticism. Kharkov.

Verkina, T. B. (2008). Actual intoning as a performance problem. The author's abstract of the dissertation on acquiring a scientific degree of the Candidate of Art Criticism. Odessa.

Vezhbitskaya, A. (1996). Language. Culture. Cognition: translated from English. Moscow: Rus. dictionaries.

Zhukov, I. (2007). Life lessons. Academy of Music, 1, 39-47. 